\title{
Effect of interval training programme on pulse pressure in the management of hypertension: a randomized controlled trial
}

\author{
*Sikiru L ${ }^{1}$, Okoye GC ${ }^{2}$
}

1. Department of Biomedical Technology, School of Health Technology, Federal University of Technology, Owerri, Nigeria

2. Department of Medical Rehabilitation, Faculty of Health Science and Technology, University of Nigeria, Enugu Campus, Enugu, Nigeria

\begin{abstract}
Background: Pulse pressure (PP), might be a stronger determinants of cardiovascular risk. Objective: To investigate the effect of interval training program on PP in subjects with hypertension.

Methods: Two hundred and forty five male patients with mild to moderate (Systolic Blood Pressure [SBP] between 140179 \& Diastolic Blood Pressure [DBP] between 90-109 mmHg) essential hypertension were age-matched and grouped into exercise and control groups. The exercise (work: rest ratio of 1:1) groups involved in an 8-weeks interval training programs of between 45-60 minutes, at intensities of 60-79\% of HR max (maximum heart rate), while the control group remained sedentary during this period. SBP, DBP, $\mathrm{VO}_{2}$ max and PP were assessed.

Results: Findings of the study revealed significant correlation between PP and blood pressure; correlation of PP with SBP was much stronger (95\% variance). Also, there was significant effect of the exercise training program on SBP, DBP and PP. Changes in $\mathrm{VO}_{2}$ max also negatively correlated with changes in $\mathrm{PP}(\mathrm{r}=-.285)$ at $\mathrm{p}<0.05$.

Conclusion: Moderate intensity interval training programs is effective in the non-pharmacological management of hypertension and may prevent cardiovascular event through the down regulation of PP in hypertension.

Key words: Hypertension, Interval exercise, pulse pressure, cardiovascular risk factor, Blood pressure.

African Health Sciences 2013; 13(3): 571 - 578 http://dx.doi.org/10.4314/ahs.v13i3.7
\end{abstract}

\section{Introduction}

Hypertension is a primary risk factor for coronary heart disease, stroke, congestive heart failure, renal failure and peripheral vascular disease ${ }^{1}$. The two measures of blood pressure which represent the peak and trough of the sinusoidal wave form of arterial pressure are systolic blood pressure (SBP) and diastolic blood pressure (DBP) respectively. Although, both measurements predict cardiovascular risk, there is no a priori reason for supposing that either provides the best possible measure of risk, especially, since one (systolic) is a stronger predictor than the other ${ }^{2}$. According to O'Rourka ${ }^{3}$, Safan and Frohlich ${ }^{4}$, mean blood pressure or pulse pressure (PP), might be stronger determinants of cardiovascular risk but are not directly obtain from current clinical measurements. However, PP can be

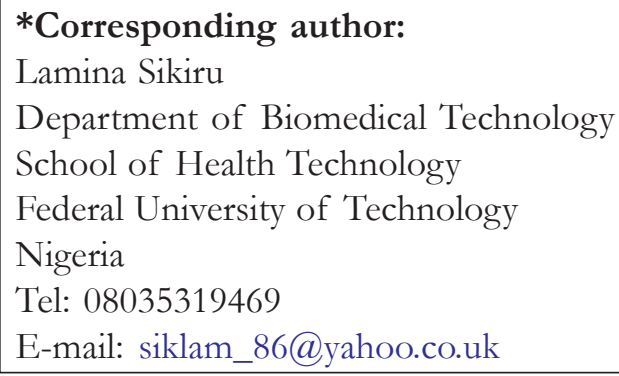

mathematically expressed as the difference between $\mathrm{SBP}$ and $\mathrm{DBP}^{5}$.

Studies have reported a clear association between PP and cardiovascular risk ${ }^{6,7}$. These reports are consistent with the pathophysiological processes in the conduit vessels and heart of patients with hypertension, especially in older subjects with systolic hypertension and increased arterial stiffness. ${ }^{5}$ It has been previously shown in a large French population that in male subjects aged 40 to 69 years; increased pulse pressure (PP) was a strong predictor of general and cardiovascular mortality, especially coronary mortality ${ }^{6}$. Data from previous studies on hypertension ${ }^{7}$, suggest that PPitself could be a major predictor of cardiac risk in different populations. Studies ${ }^{8,9}$ have recommended various therapies including exercise in the management of hypertension. However, studies investigating the relationship of PP, blood pressure and cardiovascular fitness in black African population seem scanty.

Therefore, the purpose of this study was to investigate the effect of interval training on blood pressure and pulse pressure (PP) in the management of hypertension. For the purpose of this study, three 
major null hypotheses were formulated and tested: (1) there would be no significant correlation between PP, SBP and DBP, (2) there would be no significant effect of interval exercise on PP. (3) there would be no significant correlation between exercise changes in $\mathrm{PP}$ and changes in $\mathrm{VO}_{2} \max$

\section{Method}

In the present study, age-matched randomized double blind independent groups design was used to determine the influence of the interval exercise on cardiovascular parameters. A week wash out period was established and pretest was administered to all subjects on the last day of the wash out period. Following wash out and pretest, all subjects were placed on methyldopa, the exercise group involved in interval training programs for 8 weeks, while the control group remained sedentary during the period. At the end of the training and sedentary period, another one week wash out period was established and posttest was administered to all subjects on the last day of the wash out period.

Population for the study was male essential hypertensive subjects attending the hypertensive clinic of Murtala Muhammed Specialist Hospital Kano Nigeria. Subjects gave their informed consent in accordance with the American College of Sports Medicine (ACSM) guidelines. ${ }^{10}$ Ethical approvals were granted by the Ethical Committee of Kano State Hospitals Management Board and the faculty of Health Sciences, College of Medicine, University of Nigeria, Enugu Campus.

Only those who volunteered to participate in the study were recruited. Subjects between the age range of 50-70 years with chronic mild to moderate and stable ( $>1$ year duration) hypertension (SBP between 140-179 \& DBP between 90-109 $\mathrm{mmHg}$ ) were selected. Subjects who had stopped taking antihypertensive drugs or on a single antihypertensive medication were recruited for the study were also recruited. All subjects were sedentary and have no history of psychiatry or psychological disorders or abnormalities.

Underweight and obese (BMI $<18.5 \&>$ $30 \mathrm{~kg} / \mathrm{m}^{2}$ respectively), smokers, alcoholic, diabetic, other cardiac, renal, respiratory disease patients were excluded. Those involved in vigorous physical activities and above averagely physically fit $\left(\mathrm{VO}_{2} \max \right.$ $>27 \&>33 \mathrm{ml} / \mathrm{kg} \cdot \mathrm{min}$ for over $60 \& 50$ years old respectively) were also excluded.

A total of 323 chronic and stable, essential mild to moderate male patients with hypertension satisfied the necessary study criteria. Subjects were age-matched and randomly grouped into exercise (162) and control (161) groups.

All subjects on anti-hypertensive drugs were asked to stop all forms of medication and in replacement, were given placebo tablets (consisted of mainly lactose and inert substance) in a single blind method $^{11,12}$. All subjects including those not on any antihypertensive medications were placed on placebo tablets for one week (7 days).

Subjects resting BP (SBP, DBP \& HR) was monitored from the right arm as described by Walker et $\mathrm{al}^{13}$ using an automated digital electronic BP monitor (Omron digital BP monitor, Model 11 EM 403c; Tokyo Japan). PP was obtained by subtracting DBP from SBP. ${ }^{14}$

The Young Men Christian Association (YMCA) sub-maximal cycle ergometry test protocol was used to assess subject's aerobic power as described by ACSM ${ }^{15}$, Golding et al ${ }^{16}$.

The test procedure was conducted in the Department of Physiotherapy of Murtala Mohammed Specialist Hospital (MMSH), Kano between 8:00 am and 10:00 am.

Following stress test and prior to the exercise training, all subjects in the exercise and control groups were re-assessed by the physician and were prescribed with aldomet (methyl-dopa) as necessary. During the training and sedentary period ( 8 weeks) all subjects in the interval, continuous and control groups were placed on methyldopa according to their prerecruitment doses and responses at $250 \mathrm{mg}$ and $500 \mathrm{mg}$ daily. Methyldopa was preferred because it does not alter normal hemodynamic responses to exercise. ${ }^{17}$. It is a well-tolerated and mostly prescribed antihypertensive drug in Nigeria ${ }^{18}$, particularly Northern Nigeria where the study was conducted and it is also useful in the treatment of mild to moderately severe hypertension. ${ }^{19}$ Subjects maintained these prescriptions with regular medical consultation and observation throughout the period of this study.

\section{The exercise group (group 1)}

After a 10-minutes warm up (pedaling at zero resistance), subjects in the exercise group exercised on a bicycle ergometer at a moderate intensity of between $60-79 \%$ of their HR max (maximum heart rate). ${ }^{20,21}$ that were estimated as stated below, from 220 minus the age of a subject as recommended by ACSM. ${ }^{22}$ The starting workload was $100 \mathrm{kgm}(17$ watts) which was increased at a pedal speed of 
$50 \mathrm{rpm}$ to obtain $60 \%$ of their HR max was increased in the first two weeks to and level up at $79 \%$ of their HR max and this value was maintained throughout the remaining part of the training period at a work: rest duration of 1:1 of 6 minutes each. ${ }^{24}$ During the 6-minutes rest interval period, subjects pedal at zero intensity. The initial of exercise session was increased from 45 minutes in the first two weeks of training to and leveled up at 60 minutes throughout the remaining part of the training. Following the exercise, another 10- minutes cool down was established by pedaling at zero resistance. Exercise session of three times per week was maintained throughout the 8 weeks period of training.

\section{The control group (group 3)}

Subjects in the control group were instructed not to undertake any organized/structured physical activity apart from the activity of daily living during the 8 weeks period of study.

\section{Wash out period}

At the end of the 8 weeks training and sedentary period, all subjects remained sedentary (no exercise) and were asked to stop methyldopa. Subjects were instead prescribed with placebo tablets in a single blinded method for one week in order to get rid the effect of the methyldopa taken during the training period.

Post training physiological (SBP and DBP) assessment and stress test were conducted as earlier described in the pretest procedures using standardized protocols, techniques and methods by the same investigators.

All pre and post test measurements were recorded on a data sheet. Two hundred and forty five subjects (140 from exercise and 105 from control groups) completed the eight weeks training program. Seventy eight subjects (22 from exercise and 56 from control groups) had dropped out because of noncompliance, unfavorable responses to methyldopa and exercise training or had incomplete data; therefore, the data of 245 subjects were used in the statistical analysis (figure 1).

Following data collection, the measured and derived variables were statistically analyzed. The descriptive statistics (Means \& standard deviations) of the subjects physical characteristics, estimated $\mathrm{VO}_{2}$ max and other cardiovascular parameters were determined. Independent $t$ test was conducted to assess the treatment outcome. Pearson product moment correlation test was also computed for the variables (changes in $\mathrm{PP}, \mathrm{BP} \&$ changes in $\mathrm{VO}_{2} \max$ ) of interest. In the t-test and correlation tests, the difference between subjects post-training and pretraining measurements (changed score) were used as dependent measures. All statistical analysis was performed on a Toshiba compatible microcomputer using the statistical package for the social science (SPSS), windows Version 16.0 Chicago IL, USA. The probability level for all the above tests was set at 0.05 to indicate significance.

\section{Results}

The subject's age ranged between 50 and 70years. Mean age, height, weight and BMI \pm SD: exercise group (58.40 \pm 6.91 years, $167.78 \pm 7.81 \mathrm{~cm}$, $\left.70.18 \pm 11.37 \mathrm{~kg}, 24.96 \pm 3.88 \mathrm{~kg} \cdot \mathrm{m}^{-2}\right)$ and control group $(58.27 \pm 6.24$ years, $167.89 \pm 5.31 \mathrm{~cm}$, $\left.68.47 \pm 17.07 \mathrm{~kg}, 24.16 \pm 4.91 \mathrm{~kg} \cdot \mathrm{m}^{-2}\right)$. There was no significant difference in age between groups $(\mathrm{t}=.156$, $\mathrm{p}=.876$ ).

Subject's pre versus $(\mathrm{Vs})$, post treatment mean $\mathrm{BP} \pm \mathrm{SD} \mathrm{mmHg}$, PP and $\mathrm{VO}_{2}$ max ml.kg${ }^{1} . \mathrm{min}^{-1}$ for the exercise (SBP166.05 \pm 14.10 ; DBP, $96.80 \pm 3.38$; PP, 69.25 13.29 \& $\mathrm{VO}_{2} \max$

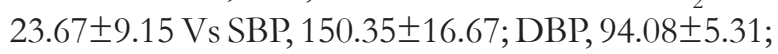
PP, 56.27 $\left.15.09 \& \mathrm{VO}_{2} \max 37.46 \pm 7.42\right)$ group and control (SBP160.87 \pm 13.23 ; DBP, 97.17 \pm 1.43 ; PP, $63.70 \pm 12.21 \& \mathrm{VO}_{2} \max 21.23 \pm 5.76 \mathrm{Vs}$ SBP, 163.47 \pm 14.88 ; DBP, $96.10 \pm 2.67$; PP, 67.37 \pm 14.12 \& $\mathrm{VO}_{2} \max 22.82 \pm 7.44$ ) group (table 1).

Table 2 students' test results indicated a significant reduction in the exercise groups over control in SBP $(\mathrm{t}=13.148, \mathrm{p}=0.000), \mathrm{DBP}(\mathrm{t}=-6.560$, $\mathrm{p}=0.000), \mathrm{PP}(\mathrm{t}=-10.790, \mathrm{p}=0.000)$ and $\mathrm{VO}_{2} \max$ $(\mathrm{t}=11.959, \mathrm{p}=0.000)$ at $\mathrm{p}<0.05$.

Results showed significant positive correlation between baseline PP and BP; SBP ( $r=$ .971) and DBP ( $r=.214)$; the correlation of PP with SBP was much stronger ( $95 \%$ variance). Result also showed significant negative correlation between changes in PP and changes in $\mathrm{VO}_{2} \max (-.198)$ at $\mathrm{p}<0.05$ (figure $2 \& 3$ ). 


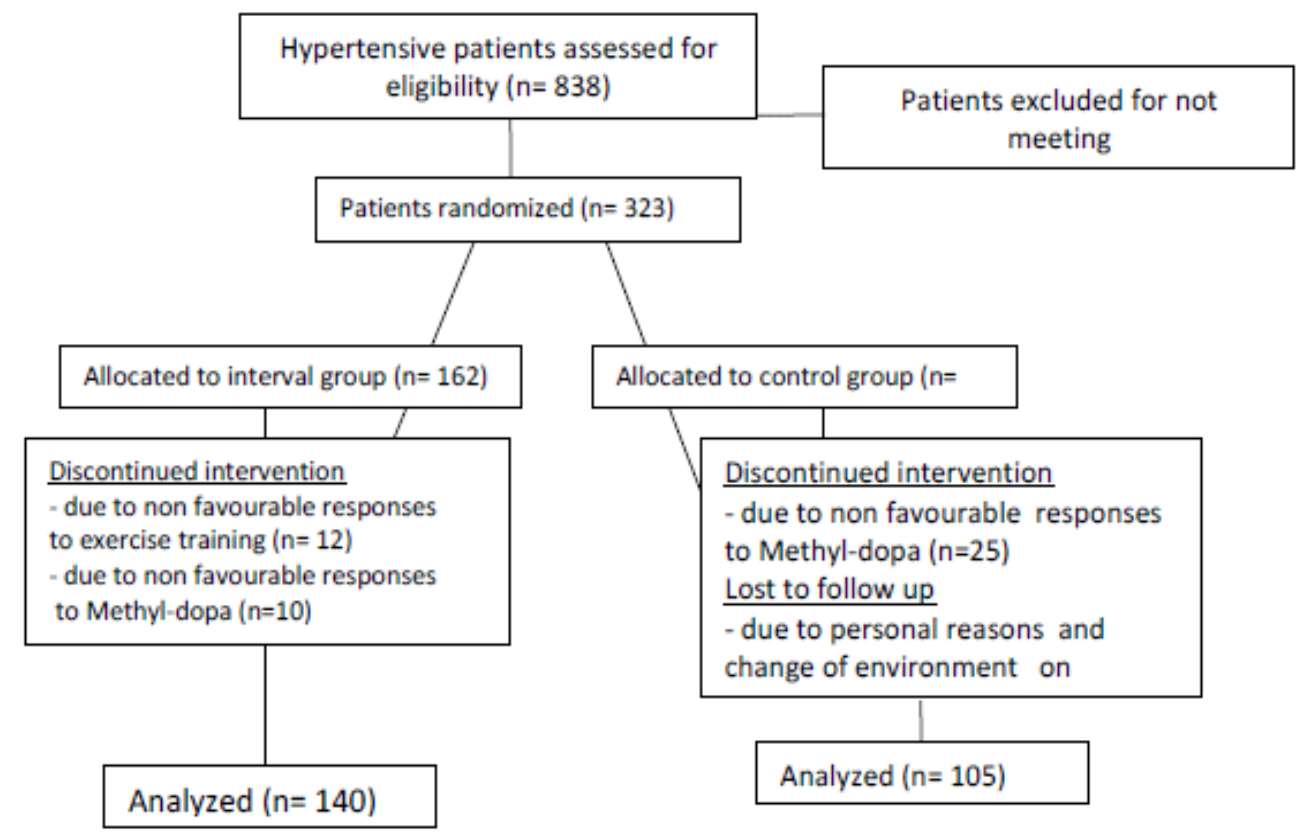

Figure 1: Study design flow chat

Table 1: Groups pre and posttest mean $(\mathrm{X}) \pm$ standard deviation $(\mathrm{SD})(\mathrm{N}=245)$

\begin{tabular}{lcclll}
\hline Variables & \multicolumn{2}{c}{ Exercise group } & & \multicolumn{2}{c}{ Control group } \\
& $\mathrm{X} \pm \mathrm{SD}(\mathrm{n}=140)$ & & & \multicolumn{2}{c}{$\mathrm{X} \pm \mathrm{SD}(\mathrm{n}=105)$} \\
\cline { 2 - 3 } \cline { 5 - 6 } & Pretest & Posttest & & Pretest & Posttest \\
\hline $\mathrm{SBP}(\mathrm{mmHg})$ & $166.05 \pm 14.10$ & $150.35 \pm 16.67$ & & $160.87 \pm 23.91$ & $163.47 \pm 14.88$ \\
$\mathrm{DBP}(\mathrm{mmHg})$ & $96.80 \pm 3.38$ & $94.08 \pm 5.31$ & & $97.17 \pm 7.20$ & $96.10 \pm 2.67$ \\
$\mathrm{VO}{ }_{2} \mathrm{max}(\mathrm{ml} / \mathrm{kg} / \mathrm{min})$ & $23.67 \pm 9.15$ & $37.46 \pm 7.42$ & & $21.23 \pm 5.76$ & $22.82 \pm 7.44$ \\
$\mathrm{PP}(\mathrm{mmHg})$ & $69.25 \pm 13.29$ & $56.27 \pm 15.09$ & & $63.70 \pm 12.21$ & $67.39 \pm 14.12$ \\
\hline
\end{tabular}

Table 2: Groups changed scores mean(X) \pm standard deviation (SD) and t-test values $(\mathrm{N}=245)$

\begin{tabular}{llllll}
\hline Variables & \multicolumn{2}{c}{$\begin{array}{c}\text { Changed score values } \\
\mathbf{X} \pm \text { SD }\end{array}$} & & t-values & p-values \\
\cline { 2 - 3 } & $\begin{array}{c}\text { Exercise group } \\
\mathrm{n}=140\end{array}$ & $\begin{array}{c}\text { Control group } \\
\mathrm{n}=105\end{array}$ & & \\
\hline $\mathrm{SBP}(\mathrm{mmHg})$ & $-15.70 \pm 13.16$ & & $2.61 \pm 7.85$ & -13.148 & $0.000^{*}$ \\
$\mathrm{DBP}(\mathrm{mmHg})$ & $-4.01 \pm 4.34$ & & $-1.07 \pm 1.76$ & -6.560 & $0.000^{*}$ \\
$\mathrm{VO}_{2} \mathrm{max}(\mathrm{ml} / \mathrm{kg} / \mathrm{min})$ & $13.79 \pm 9.99$ & & $1.59 \pm 3.52$ & 11.959 & $0.000^{*}$ \\
$\mathrm{PP}(\mathrm{mmHg})$ & $-12.98 \pm 13.95$ & & $3.67 \pm 8.50$ & 10.790 & $0.000^{*}$ \\
\hline
\end{tabular}

$*$ Significant, $\mathrm{p}<0.05$ 


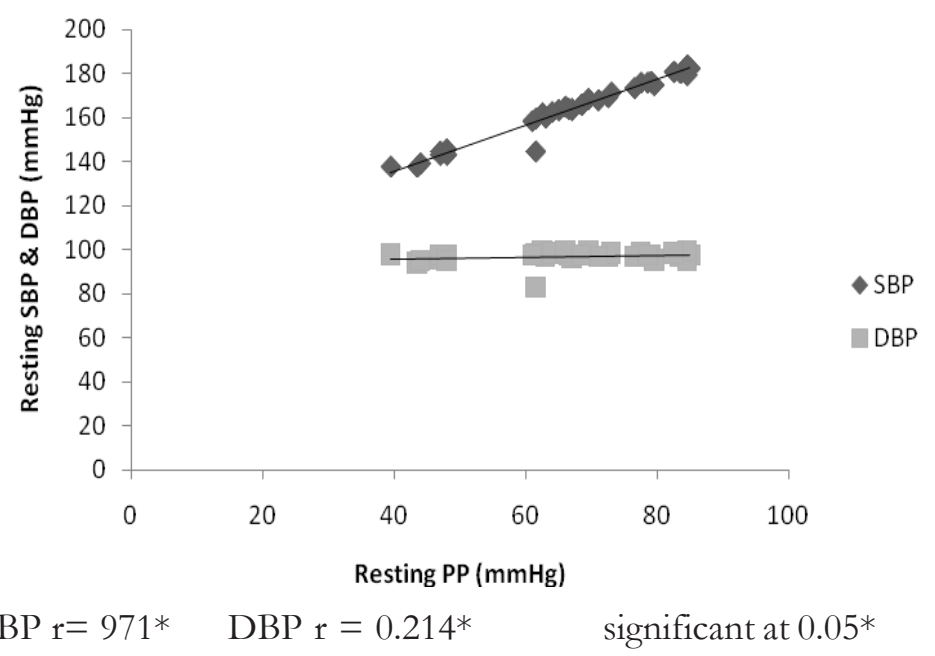

Figure 2: Correlation between baseline (pretest) $\mathrm{VO}_{2} \max , \mathrm{SBP}$ and DBP $(\mathrm{n}=140)$.

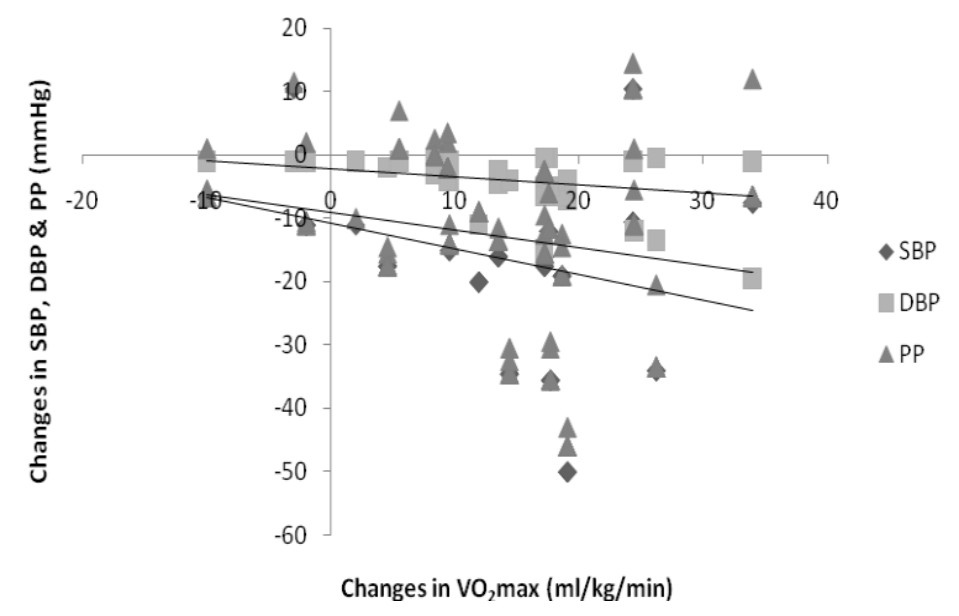

SBP $r=-.971 *$ DBP $r=-0.304 * * \quad$ PP $r=-.289 * * \quad$ significant at $0.05 *$ significant at $0.01 * *$

Figure 3: Correlation between training changes in $\mathrm{VO}_{2} \max , \mathrm{SBP}, \mathrm{DBP}$ and PP $(n=140)$.

\section{Discussion}

The purpose of the present study was to test three null hypotheses as earlier stated. This study provide evidence that (1) PP is significantly correlated with both SBP and DBP (2) exercise significantly reduced $\mathrm{PP}$ and (3) changes in PP significantly correlated with changes in $\mathrm{VO}_{2}$ max.

$\mathrm{PP}$ as defined in this study is derived by the difference between two primary variables (SBP and DBP), and hence a correlation between PP and the two primary variables is statistically expected. It was also expected that each primary variable will contribute about equally to the variability of PP. The situation is analogues but not identical with the well recognized problems in studying changes of a variable from baseline, in which a derived variable is also calculated by the difference. The present study confirmed that the expected correlations were present, but the correlation of PP with SBP was much stronger than with DBP. Our finding is in agreement with the report of Miller et $\mathrm{al}^{5}$; they reported that $90 \%$ of the variance in PP was explained by SBP.

To eliminate selection bias by previous study $^{5}$, we selected subjects with mild (stage 1) to moderate (stage 2) hypertension (SBP [140 -179], DBP [90-109]), ${ }^{1}$ yet, the correlation of PP with SBP was much stronger, such that $93 \%$ of the variance in PP was explained by SBP. Reason for this high SBP variance in PP by our study could be the result of wider range of SBP $(179-140=39 \mathrm{mmHg})$ compared to DBP $(109-90=19 \mathrm{mmHg})$. Also, PP 
estimate from the difference of SBP and DBP in the present study is not identical to pulse wave amplitude. The clinical measurement of PP by sphygmomanometer produces a value which is only indirectly and approximately related to the real and direct measurement of PP. The administrative and technical lag in the use of sphygmomanometer could not be ruled out; the use of direct methods such as aplanation tonometry seems more promising. ${ }^{5}$

Another probable reason for high variance of SBP in PP might be age, many observational studies evaluating the changing pattern of blood pressure with the aging process have shown a concomitantincrease in systolic blood pressure (SBP), diastolic blood pressure (DBP), and pulse pressure (PP) until middle adult life. Beyond the approximate age of 60 years, SBP continues to increase but DBP reaches a plateau or gradually falls, and this leads to an accelerated rise in PP. ${ }^{23}$

Results of the present study revealed significant reduction in interval group PP over control group. A similar result was reported by Mughal et $\mathrm{al}^{11}$; they investigated the effects of aerobic exercise in patients with essential hypertension. 12weeks aerobic exercise intervention trial was conducted, to examine the influence of brisk walking on resting pulse pressure, mean arterial blood pressure in patients with essential hypertension. Twenty-seven men with stage 1 or 2 essential hypertension (not on antihypertensive medication) participated in the study. The aerobic exercise training protocol consisted of 30 minutes of brisk walking 3 to 5 times per week, at $50 \%$ of $\mathrm{VO}_{2} \max$ on an ergometer cycle. They reported statistically significant decrease in pulse pressure from baseline value of $3.7 \mathrm{mmHg}$, ( $<<0.01)$. They concluded that aerobic exercise caused small reductions in PP in men with stage 1 or 2 essential hypertension.

The general consensus is that regular aerobic exercise reduces blood pressure significantly in patients with mild-to-moderate essential hypertension.

${ }^{24}$ However, apart from blood pressure reduction; our results also complement several others on the therapeutic role of exercise in cardiovascular event risk factor modification.

\section{Clinical implication}

SBP, DBP, and PP were all strongly associated with increased risk factors for hypertension and cardiovascular risk in hypertension. $[6,7,25,26]$ There seem to be a consensus that regular physical activity can effectively and significantly control blood pressure (SBP \& DBP). ${ }^{[8,9,24]}$ Though, PP is mathematically derived from difference between SBP and DBP, ${ }^{[5]}$ however, it has been reported that $\mathrm{PP}$ is a good index of arterial stiffness ${ }^{[27}$. In spite of this fact, regular physical activity has been proved as an effective adjunct intervention with respect to blood pressure reduction; $\mathrm{VO}_{2} \max$ is an important factor that could affect arterial stiffness, exercise tolerance, functional capacity, physical work capacity, quality of life, survival and the mortality rate for cardiovascular disease and all causes of diseases in hypertension. ${ }^{[28,29,30]}$

\section{Conclusion}

Our study demonstrated a rationale bases for the adjunct role of long term moderate intensity interval exercise training in the down regulation of blood pressure and PP a major cardiovascular event risk factor. Therefore, exercise specialists and other therapists should feel confident in the use of this form of therapy in the non-pharmacological adjunct management of hypertension.

\section{Limitation of the study}

The present study demonstrated a rationale bases for the role of interval exercise training in the down regulation of the blood pressure and PP. However, the limitation of the study includes failure to perform the intension-to-treat analysis (ITTA) in the randomized controlled trial. Though, it has been reported that ITTA provides unbiased assessments of treatment efficacy; ${ }^{[31]}$ however, on-treatment analysis (per protocol analysis) has the advantage that it provides for a new treatment to show additional efficacy and it most closely reflects the scientific model underlined in the protocol. ${ }^{[32]}$ These limitation however, warrants attention in future studies.

\section{Trial Registration}

This work was registered by the Pan African Clinical Trials Registry (PACTR), with Registration number: PACTR201112000341237

\section{References}

1. Joint National Committee on Prevension, Detection, Evaluation and Treatment (JNC) of High Blood Pressure. The six report of the JNC. Arch. Intern. Med 1997; 157: 2413-46.

2. US National Heart, Lung and Blood Institute, Kannel WB, Wolfg PA, Garrison RJ (editors): Framingham study: an epidemiological investigation of cardiovascular risk factors. 30 
years follow up. NIH Publication No 87. 2073. Washington DC: US Department of Health and Human Services, April 1987.

3. O'Rourke M. Mechanical principles in arterial disease. Hypertension 1995; 26: 2-9.

4. Safar ME. Pulse pressure in essential hypertension: clinical and therapeutical implications. J Hypertens 1989; 7: 769-776.

5. Millar JA, Lever AF, Burke V (1999). Pulse Pressure as a risk factor for cardiovascular events in the MRC mild hypertension trial. Journal of Hypertension 1999; 17: 1065-1072.

6. Benetos A, Safar M, Rudnichi A, Smulyan H, Richard J-L, Ducimetiere P, Guize L. Pulse pressure: a predictor of long-term mortality in a French male population. Hypertension. 1997; 30: 1410-1415.

7. Madhavan S, Ooi WL, Cohen H, Alderman MH. Relation of pulse pressure and blood pressure reduction to the incidence of myocardial infarction. Hypertension. 1994; 23:395-401.

8. Beilin LJ, Puddy IB, Burke V. Lifestyle and hypertension. Am J Hypertens 1999; 12: 934-945.

9. Mughal M, Alvi I, Akhund I, Ansari A(2001) The effects of aerobic exercise training on resting blood pressure in hypertensive patients. J Pak Med Assoc. 51(6): 222-226.

10. American College of Sport Medicine. Guide lines for exercise testing and Prescription. $4^{\text {th }}$ Edition, Philadelphia, Lea \& Febiger.1991.

11. Townsend, RR, Mcfadden, TC, Ford, V, and Cadee, JA. A randomized double blind, placebocontrolled trial of casein protein hydrolysnte (C12 peptide) in human essential hypertension. American Journal of Hypertension 2004; 17:10561058.

12. Waeber, B, Nussberger, J, and Brunner, HR. The rennin angiotension system: role in experimental and human hypertension. In: Pathophysiology of hypertension: regulatory mechanisms. Zanchetti, A, and Tarazi RC, eds. Amsterdam: Elsevier, 1986. pp. 489-519.

13. Walker, AJ, Bassett, DR, Duey, WJ, Howley, ET, Bond, V, Torok, DJ, and Mancuso, P. Cardiovascular and plasma cathecolamae responses to exercise in blacks and whites. Hypertension 1992; 20(4):542-548.

14. Millar JA, Lever AF and Burke V. Pulse pressure as a risk factor for cardiovascular events in the MRC Hypertension Trial. J of Hypertension 1999; 17: 1065-1072.
15. American College of Sports Medicine. ASCM's guidelines for exercise testing and prescription $5^{\text {th }}$ Edition. Baltimore: Williams \& Wilkins, 1995.

16. Golding, LA, Meyers, CR, and Sinniny, WE. Way to physical fitness. The complete carnote to fitness testing and instruction, $3^{\text {rd }}$ Edition Champaign IL: Human Kinetics Publishers, 1989.

17. Katzung, BG. Basic and clinical pharmacology. $7^{\text {th }}$ ed. New York: Lange Medical Books/Craw Hill, 1998.

18. Mancia, G, Ferari, L, Gregorini, L, Leonett, L, Terzoli, L, Biachini, C, and Zanchetti, A. Effects of treatment with methyldopia on basal haemodynamic and on rural control. In: The therapeutics of hypertension Robertson JS, Pickering GW, Goldwell ADS, eds. London: Royal Society of Medicine and Academic Press Inc, Ltd. 1980. pp. 70-78.

19. Salako, LA. Treatment of hypertension: cardiovascular disease in Africa. Ibadan: Ciba Geigy Ltd, 1976.

20. American College of Sports Medicine. Physical activity, physical fitness, and hypertension. Med Sci Sports Exerc 1993; 25: i-x.

21. World Health Organization .Hypertension practice guidelines for primary care. Physician 1999; 2-9.

22. Franklin SS, Gustin WG, Wong ND, et al. Hemodynamic patterns of age-related changes in blood pressure: the Framingham Heart Study. Circulation 1997; 96: 308-315.

23. Randall OS, van Den Bos GC, Westerhof N. Systemic compliance: does it play a role in the genesis of essential hypertension? Cardiovasc Res 1984; 18: 455-462.

24. Whelton PK, Jiang He, Klag MJ. Blood pressure in westernized populations.In: Swales JD, ed. Textbook of Hypertension. London, UK: Blackwell Scientific Publications; 1994: pp. 1121.

25. Benetos A, Safar M, Rudnichi A, Smulyan H, Richard JL, Ducimetieere P, Guize L. Pulse pressure: a predictor of long-term cardiovascular mortality in a French male population. Hypertension 1997; 30:1410-1415.

26. Dyer AR, Stamler J, Shekelle RB, Schoenberger JA, Stamler R, Shekelle S, Collette P, Berkson DM, Paul O, Lepper MH, Lindberg HA. Pulse pressure, III: prognostic significance in four Chicago epidemiologic studies. J Chron Dis 1982; 35:283-294. 
27. Corona G, Mannucci E, Lotti F, Fisher AD, Bandini E, Balercia G, Forti G, Maggi M. Pulse pressure, an index of arterial stiffness, is associated with androgen deficiency and impaired penile blood flow in men with ED.J Sex Med. 2009; 6(1): 285-93

28. Guimara es1 GV, Ciolac1 EG, Carvalho VO, D'Avila VM, Bortolotto LA and Bocchi EA. Effects of continuous vs. interval exercise training on blood pressure and arterial stiffness in treated hypertension. Hypertension Research 2010; 33, 627632
29. Evenson KR, Stevens J, Thomas R, Cai J. Effect of cardiorespiratory fitness on mortality among hypertensive and normotensive women and men. Epidemiology 2004; 15: 565-572.

30. Franz IW. Blood pressure response to exercise in normotensives and hypertensives. Canadian Journal of Sport Science. 1991; 16 (4): 296-301

31. Montori VM, Guyatt GH. Intention-to-treat principle. CMAJ 2001;165:1339-41.

32. Stewart WC, Jackson AL, Jenkins JN. Dropout rates for intent-to-treat and per protocol analyses. Am J Ophthalmol 2004;137:639-45. 